\title{
Paradigmas estéticos del teatro colombiano en el siglo $\mathbf{X X}^{1}$
}

\author{
Mauricio Doménici \\ Profesor titular \\ Universidad del Valle \\ https://orcid.org/0000-0003-2588-5522 \\ domenici.m@gmail.com
}

\section{Resumen}

El artículo es una reflexión sobre las épocas y los estilos del teatro colombiano en el siglo XX. No es tanto un recuento histórico, ni exhaustivo, ni descriptivo sobre los hechos, sino una propuesta teórica, una visión, una hipótesis sobre el conjunto de un proceso, en el que se establecen unas coordenadas y se sistematizan ciertos factores culturales y artísticos que han marcado la evolución de este teatro. En consecuencia, postulamos la existencia de cuatro paradigmas: el teatro español, el teatro moderno, el teatro de creación colectiva y el teatro posmoderno. En cada uno de ellos se pueden identificar ciertos patrones formales, un imaginario poético y una concepción social. La idea es trazar un panorama de conjunto, las líneas gruesas del camino que ha seguido el teatro nacional y sus épocas.

Palabras clave: creación colectiva; épocas y estilos; paradigmas estéticos; teatro colombiano siglo XX; teatro español; teatro moderno; visión de un proceso.

\section{Hesthetic paradigms of the Colombian theater in the twentieth century}

\section{Abstract}

The article is a reflection on the times and styles of Colombian theater in the 20th century. It is not so much a historical account, neither exhaustive, nor descriptive about the facts, but a theoretical proposal, a vision, a hypothesis about the whole of a process, in which some coordinates are established and certain cultural and artistic factors that have marked the evolution of this theater are systematized. Consequently, we postulate the existence of four paradigms: The Spanish theater, the modern theater, the theater of collective creation and the

\footnotetext{
${ }^{1}$ Procedencia del artículo: Este artículo surgió por intereses personales.
} 
post-modern theater. In each of them, certain formal patterns can be identified, a poetic imaginary and a social conception. The idea is to draw an overall panorama, the thick lines of the path that the national theater and its times have followed.

Keywords: aesthetic paradigms; Colombian theater twentieth century; collective creation; modern theater; Spanish theater; times and styles; vision of a process.

Recibido: 26 de agosto del 2020. Aprobado: 25 de febrero del 2021

Artículo de reflexión https://doi.org/10.25100/poligramas.v0i52.11419

\section{¿Cómo citar este artículo en MLH? - How to quote this article in MLA?}

Doménici, Mauricio. "Paradigmas estéticos del teatro colombiano en el siglo XX" Poligramas 52 (2021) : e.2511419. Web. Fecha de acceso (día, mes en mayúscula y abreviado, y año).

\section{Introducción}

La década del 60 en el siglo XX, es un período decisivo en la historia del teatro colombiano, por dos motivos principales: el advenimiento del teatro moderno y el nacimiento de los grupos que definieron una nueva teatralidad, la cual se propuso expresar de forma clara y deliberada nuestra historia y los hechos que nos habían constituido como nación. Estos grupos estables, en su mayoría vivos hasta hoy, definieron una forma o un modo de hacer un teatro distinto, crearon una tradición propia sobre cómo era o debería ser la vida del actor, cómo se definía un repertorio con temáticas arraigadas en los conflictos de esta nación, en fin, enseñaron cómo era que se desarrollaba la lucha por construir la autonomía de un teatro que se enfrentaba a la cultura oficial. Las generaciones que vinieron después lo aprendieron de ellos o contra ellos, en una dialéctica que no se ha interrumpido y ha hecho posible el nacimiento de una dramaturgia parecida a nosotros mismos.

Teniendo en cuenta el período de los 60 como punto focal del cambio, quiero mostrar en este artículo la evolución que se ha producido, no tanto en la línea de un recuento pormenorizado de los hechos históricos, cosa que ya se ha realizado, sino en la perspectiva de los paradigmas estéticos seguidos por el teatro colombiano en el siglo xx. Es bueno entender 
para evitar ese nacionalismo dogmático y populista que de vez en cuando salta al escenario, que nuestro teatro, como el resto de las artes, no es el resultado de una autogeneración propia o un brote natural y espontáneo de la tierra o el "espíritu nacional", el teatro se va constituyendo en un largo proceso de influencias, intercambios y contradicciones culturales, en nuestro caso propias de América en sus relaciones con Europa y Estados Unidos. En la adopción y adaptación de un paradigma estético operan diversos factores como la tradición cultural del país, las condiciones sociales, los debates ideológicos y las nuevas corrientes estéticas internacionales, entre otros.

Cabe aclarar, también, lo siguiente: entiendo por "estética teatral", un cierto tipo de investigación o reflexión teórica sobre las épocas y los estilos teatrales en las dinámicas de su evolución. Como dice Peter Szondi, se trata de percibir la forma dramática como algo vinculado a la historia (68-69). En esta orientación estratégica mi hipótesis es que podemos identificar en la historia del teatro colombiano del siglo xx, cuatro paradigmas estéticos: el teatro español, el nuevo teatro, el teatro de creación colectiva y el teatro pos-dramático. En cada uno de ellos se pueden identificar ciertos patrones formales, un lenguaje particular, un imaginario poético, una concepción social, unas convenciones, una fuerza motriz o principio poético determinante en las obras y en los autores-directores más representativos. No pretendo ser exhaustivo, ni demostrativo en la descripción de cada "estilo", solo intento trazar un panorama indicativo, sintomático, del proceso que se ha vivido, seleccionando los nombres más representativos.

\section{Paradigma del teatro español}

El primer paradigma a identificar corresponde al teatro español, el cual ha estado presente desde la colonia hasta la primera mitad del siglo xx. Las relaciones con el teatro español han sido paradójicas, de negación y sumisión según el clima de polarización política del momento. Al llegar la década del 50 de clara hegemonía conservadora, los hechos indican su indiscutible presencia y su importancia. Ahora bien, la historia del teatro español es una historia extraordinariamente rica e intensa, pasa desde el Siglo de Oro por muchas épocas y diversidad de géneros, autores, resulta en consecuencia esencial determinar a qué tipo de teatro en particular puede ser referido este paradigma.

Hagamos primero una extraña y tal vez insólita digresión que pronto revelará su pertinencia. Hay en Cien años de soledad de García Márquez unas pocas referencias al teatro, 
pero allí están como parte de un mundo primigenio, como un elemento cultural de las cosas que pasan y definen a Macondo. Sabemos que este es un lugar mítico o metafórico, los tiempos están mezclados o superpuestos, comprimidas en cien años se incluyen seis generaciones, la época en que se enmarcan va desde las guerras civiles del siglo xix hasta la violencia de los años 50, son límites imprecisos, abiertos, circulares, la saga de los Buendía es una transfiguración poética y allí se incluye este relato que nos interesa: poco después de terminada la guerra, el primer teatro que se construyó en Macondo lo hizo Bruno Crespi, el próspero italiano de la tienda de juguetes e instrumentos musicales, un teatro, y esto es lo importante, que solo ocupaban las compañías españolas en sus itinerarios del sur del continente. Cuando dejaron de venir el teatro se convirtió en una sala de cine.

El director teatral e historiador del teatro colombiano, Fernando González Cajíao, señala cómo a pesar que hubo muchos dramaturgos en la primera mitad del siglo xx en Colombia, la actividad teatral, como hecho material, vivo, es decir, el estreno de obras, el conocimiento del oficio actoral, la organización del espectáculo, los recursos técnicos, los códigos escénicos, dependía todo en gran medida del arribo de las compañías españolas (697-707). Otro dato que muestra esta situación: en el año de 1955 con la creación de la Escuela Departamental de Teatro de Bellas Artes de Cali, se invita como su primer director al español Cayetano Luca de Tena, un inicio no obstante traumático, en tanto que va a permanecer escasamente un año. Vino, vio y se fue. Este hombre era en su momento un director teatral ampliamente reconocido, vinculado al teatro de Madrid.

Dónde va a estar el problema: a diferencia del teatro europeo, el teatro español a fines del siglo xix y primeras décadas del xx, no contó con una corriente de grandes reformadores escénicos como fueron Stanislavski, Appia, Gordon Craig, Artaud, Antoine, en fin, la escena española continuó dominada por las grandes compañías que funcionaban en torno a grandes actrices o actores, estrellas luminosas, verdaderas divas-empresarias que no se arriesgaban a cambiar el modelo del lucrativo teatro comercial dominante. A estas compañías se debe, como ha dicho Cesar Oliva en su Historia del arte escénico, el gastado y anquilosado teatro comercial español de entonces (320-322).

Este tipo de teatro va a estar representado en Colombia por los dos dramaturgos más relevantes y representativos de la primera mitad del siglo xx: Antonio Álvarez Lleras y Luis Enrique Osorio. El primero tuvo una larga carrera, estrenó su primera obra "Vívoras Sociales" 
en 1911 y la última "El virrey Solís" en 1948. En el libro de Marina Lamus Bibliografía anotada del teatro colombiano, se lee cómo la mayor parte de las obras de Álvarez Lleras fueron estrenadas por compañías españolas, así la comedia "Alma joven" por la Compañía Adams en 1912; el drama "Como los muertos" por la Compañía Jacinto Benavente en 1916; el drama "Los mercenarios" por la Compañía Adams Nieva en 1924; el drama "Almas de ahora" por la Compañía Baus en 1941; y el drama histórico "El Virrey Solís" estrenado por la Compañía María Guerrero en 1948 (32-37).

Como dramaturgo la obra de Álvarez Lleras se ubica en lo que los historiadores españoles como Cesar Oliva y Francisco Ruiz Ramón denominan "alta comedia". Algunos investigadores nacionales han planteado situarlo en correspondencia histórica con el "naturalismo" europeo, tipo Ibsen o Chejov, pero un examen más riguroso no lo sostiene. La "alta comedia" tendrá como su máximo representante al gran Jacinto Benavente (1866-1954), señalado como un dramaturgo sin acción, ni pasión, un teatro retórico, de esgrima verbal, de salón burgués, como se ha dicho. La valoración posterior de su teatro ha sido muy crítica y demoledora, no obstante, su poderosa presencia e influencia, con un gran éxito de público. En este modelo se inscribe el teatro de Álvarez Lleras, un tipo de drama convencional, melodramático, socialmente conciliador, pero, sobre todo moralizante, con lo cual se hizo insoportable para las generaciones venideras.

Con Luis Enrique Osorio el teatro nacional se hace más popular e intenta la sostenibilidad económica de un grupo propio: crea dos Compañías teatrales y a finales de los 50 construye el edificio del Teatro de la Comedia que remodelado todavía existe hoy en Bogotá en manos del Teatro Libre de Ricardo Camacho. Al igual que Álvarez Lleras una buena parte de su producción dramática la estrenan las compañías españolas, su nexo con el paradigma que venimos describiendo es, todavía, más evidente: su comedia dramática "El amor de los escombros" fue estrenada por la Compañía Gobelay Fábregas en 1921 y publicada en 1922, con un prólogo de nadie menos que Don Jacinto Benavente; la comedia "El loco de moda", estrenada por la Compañía Sanchez Winer en 1924; el sainete lírico "La ciudad alegre y coreográfica" estrenada pos la Compañía Palou-Planells en 1918, título sintomáticamente parecido al de "La ciudad alegre y confiada" de Benavente, estrenada en Madrid en 1916 con un éxito apoteósico; varias de sus obras, el mismo Osorio las clasifica como "alta comedia", es el caso de "Nudo ciego" y de "Aspacia, cortesana de Mileto". En su trayectoria el teatro de 
Osorio se va haciendo más un teatro de sátira costumbrista y en esa dirección adopta las convenciones del "género chico", ya en decadencia en la península, pero, que algunos le dan su último aliento como en las obras de Carlos Arnichez (1866-1943), los hermanos Álvarez Quintero y Pedro Muñoz Seca. En general un teatro de estereotipos, grotesco, moralista, costumbrista, folklórico, un teatro de consumo y muy popular. Este paradigma del teatro español de la primera mitad del siglo xx fue tan difícil de tocar que los que intentaron cambiar algo chocaron con una poderosa barrera que los arrojó a la marginalidad, es el caso de Valle-Inclán quien en 1927 declaró con sorna: “. . . quisiera que toda reforma en el teatro español comenzara por el fusilamiento de los Quintero".

\section{Paradigma del nuevo teatro}

Los analistas e historiadores del teatro colombiano coinciden en señalar que con la llegada a Bogotá del japonés Seki-Sano en 1957 se da inicio al proceso de incorporación del teatro moderno en nuestro país. Este maestro se había formado en el Teatro de Arte de Moscú, en la escuela de Konstantin Stanislavski e introdujo los nuevos conceptos de la formación del actor y el teatro Naturalista. Después se ha sabido, con mayor precisión, que también fue asistente de Meyerhold y en México fundó el Teatro del Pueblo, orientando su repertorio hacia obras progresistas y contemporáneas. Se rompió así con la herencia del teatro retórico y declamatorio del período anterior. Entre los discípulos más destacados de Seki-Sano se va a destacar por su magisterio en las generaciones posteriores, el maestro Santiago García.

De forma casi coincidente en el tiempo, en el sur de Colombia, regresa a Cali desde Buenos Aires, el joven director Enrique Buenaventura. Era el año de 1955 y trae consigo su experiencia con las danzas negras brasileras, pero, especialmente su inmersión en el teatro independiente de una metrópoli que como Buenos Aires, tenía no solo una intensa y rica vida teatral, sino una compleja organización del mundo del espectáculo, en la que al decir de Oswaldo Pellettieri coexistían tres sistemas distintos: el oficial, el comercial y el independiente (70-72). Este último era un teatro con vocación experimental y de renovación, un teatro moderno, enemigo del teatro comercial. La acción de este teatro Independiente comenzó desde 1931, pasa por varias etapas, se consolidan los nombres de dramaturgos argentinos como Roberto Arlt, Oswaldo Dragún, Agustín Cuzzani, Griselda Gambaro, entre muchos otros, acción 
que va hasta entrados los años sesenta. Tanto Seki-Sano, como el Teatro Independiente argentino, dejarán su huella en la aparición del "Nuevo Teatro" colombiano.

Otros elementos configuran el clima de cambios que se van a producir. La caída de la dictadura del General Rojas Pinilla y el inicio esperanzador del Frente Nacional que prometía el fin de la violencia política, la superación de la barbarie, la entrada de la civilización y sobre todo de una democracia moderna. En materia de educación y cultura seguíamos siendo una Nación estancada y reaccionaria, un país agrario, marcado a sangre y fuego por la polarización política. Como síntoma del aire renovador que soplaba entonces se puede citar la línea editorial de la revista "Mito", dirigida por una élite intelectual cosmopolita, en la que aparecen por primera vez los nombres de dramaturgos europeos como Sartre, Genet, Artaud, Adamov, Becket, Brecht, es decir, la línea más avanzada de las vanguardias francesa y alemana. Todo un desafío al sagrado sarcófago de la cultura católica nacional.

Muchas otras cosas comienzan a cambiar, sobre todo en Cali y Bogotá, que son en este período inicial los núcleos donde se pone en marcha el movimiento del Nuevo Teatro. Se comienza a cocinar un nuevo modo de ver y hacer el teatro. Lo primero que se puede notar es el cambio radical del repertorio que se lleva a escena: E. Buenaventura con el Teatro Escuela de Cali y luego con el TEC, monta en el año 57 "Petición de mano" de Chejov, "Casamiento a la fuerza" de Moliere y "El juez de los divorcios" de Cervantes; luego en el 58 lleva a escena "Sueño de una noche de verano" de Shakespeare; "La loca de Chaillot" de Giradoux; más adelante en el año 65 "Panorama desde el puente" de A. Miller; en el 66 "Ubu rey" de Jarry , ese mismo año "Las sirvientas" de Genet; un ritmo intenso de obras tanto clásicas (Lope, Sófocles, Shakespeare) como modernas (Prestley, Wilder, Dragún), es decir, un largo período de contacto con la materia artística del teatro clásico y contemporáneo antes desconocido en la profundidad de sus códigos escénicos, período que se cierra con el montaje de "El fantoche de Lusitania" de Peter Weis en 1969. De forma paralela o entreverada con esta dinámica, Buenaventura ha comenzado su trabajo como autor dramático: de un lado hace adaptaciones de cuentos tradicionales del pacifico colombiano, de cuentos maravillosos tradicionales y con particular interés de la narrativa costumbrista de Tomás Carrasquilla; igualmente escribe obras que están motivadas en la historia latinoamericana: "La Tragedia del Rey Cristophe", el "Requien por el Padre Las Casas", "Los papeles del Infierno" y "La Trampa”, entre otras. Una época muy prolífica. 
En Bogotá hay un proceso semejante. La prehistoria del Teatro La Candelaria (1966) ha estado constituida por la actividad teatral de dos organizaciones sucesivas: el teatro El Buho (1958) y La Casa de la Cultura (1963) entre las cuales hay una línea de continuidad que estructura su experiencia. El repertorio que se monta obedece al criterio de hacer, conocer y divulgar el teatro moderno y universal: dramaturgos como M. Ghelderode, T. Wilder, O'Neill, Brecht, Lorca, A. Wesker, E. Albee, P. Weis, Shakespeare, Chejov, Pirandello, Arrabal, Esquilo, Valle-Inclán, muchos otros, inmersos en una amalgama revuelta y compleja en su diversidad dramática y cultural.

Otro factor aglutinante del proceso modernizador va a ser los festivales de teatro que van a marcar con fuerza todo el período. En 1957, con el apoyo de las Embajadas, se inaugura el "Festival Internacional de Teatro" en Bogotá, cuya naturaleza abierta al teatro europeo y norteamericano, señala su propósito de contribuir a la renovación de la escena nacional. Se realizan 6 festivales cuyo repertorio dominante recoge los nombres de los autores antes señalados y en los que participan tanto el Teatro Escuela de Cali, como El Buho de Bogotá. Este festival tenía respaldo oficial, se realizaba con bombos y platillos en el Teatro Colón y en la junta organizadora había importantes políticos liberales y conservadores, todo ello en la atmósfera de reconciliación del reciente pacto de gobernabilidad política. El último festival se realizará en 1962 y para entonces el clima político ya está enrarecido.

En Cali entre el año de 1961 y 1968 se realizan los "Festivales de Arte", originalmente por iniciativa del Instituto de Bellas Artes que ya para entonces tenía cuatro escuelas de formación: música, plásticas, teatro y danza. Los festivales se orientaron principalmente hacia la música y las artes plásticas, pero, el teatro estará presente con el TEC y el ballet moderno con el grupo de Brinati. Estos festivales tendrán un gran impacto local y sacudirán a fondo el rancio tradicionalismo en el que dormía la vieja ciudad señorial. Es la época del grupo de artistas, escritores y cineastas de "Ciudad Solar" y del mítico cine club de Andrés Caicedo cuyo nombre significa el de una generación rebelde. El festival dejará una huella profunda de liberalidad, modernidad y apertura democrática que nunca más se volverá a sentir.

En los años 60 se crean innumerables grupos de teatro en las universidades colombianas: en Bogotá el grupo de la Universidad Nacional dirigido por Santiago García; en el Externado estará el grupo dirigido por Carlos José Reyes; en Los Andes el dirigido por Ricardo Camacho y en Cali, entre muchos otros, los grupos de la Universidad del Valle y la Santiago de Cali. Esta 
"fiebre" del teatro universitario conduce en el año de 1966 a la creación de los "Festivales Nacionales de Teatro Universitario" a realizarse en Manizales. Cada universidad tiene su grupo de teatro y estos son centros de discusión política, en una época que el historiador Eric Hobsbawm ha denominado de "revolución cultural", la juventud a partir de ahora se convierte en un grupo social independiente y radical simbolizado en el "mayo del 68" en Francia, jóvenes iconoclastas, divorciados de su pasado, la consigna era la liberación personal y la liberación social, esta última empujada en América Latina por el reciente triunfo de la Revolución Cubana, liderada por un grupo de jóvenes no mayores de 30 años y del otro lado del mundo la paradójica Revolución Cultural China, dictada desde arriba por un anciano líder como Mao Zedong y realizada por las masas de jóvenes iracundos del partido comunista Chino. Ambas con un profundo impacto psicológico en el movimiento estudiantil colombiano. Con raras excepciones será un teatro agitacional, una tribuna de los debates ideológicos de las distintas organizaciones de la izquierda nacional, un teatro de "cartel" y "consigna" que buscó su público en los sindicatos, asambleas comunales, organizaciones campesinas y reivindicó su carácter amateur, su interés por el teatro como acción social, como parte de un proyecto político más amplio y no tuvo interés en el teatro como una profesión artística autónoma. Como lo ha descrito Guillermo Alberto Arévalo en sus análisis del teatro colombiano: "este teatro que tuvo un auge entre 1967 y 1973 configuró su hacer teatral, su repertorio, en los postulados del teatro didáctico de Bertolt Brecht y en el teatro documento de Peter Weis".

¿Qué es lo "nuevo" que aparece como experiencia histórica determinante en la cultura teatral de finales de los años 50 y en el transcurso de los 60? ¿En qué sentido concreto se puede hablar de un nuevo paradigma? Para un crítico tan agudo como Jaime Mejía Duque este es un fenómeno que surge de súbito, este masivo "fervor" teatral, en un contexto donde no había una tradición escénica propia, no había espacios de desarrollo para un arte complejo, no había actores, escenógrafos, dramaturgos, escuelas, es algo espontaneo, diletante, el teatro seguía siendo un ideal (460-461). En verdad sí habían existido dramaturgos, pero, no habían sido verdaderos hombres de teatro, como el caso del político Rafael Núñez o del novelista José Eustasio Rivera, escribieron teatro, pero, su vida no estaba en el teatro. Sobre las causas de este fenómeno el investigador y académico Guillermo Alberto Arévalo las atribuye al atraso y aislamiento de nuestra cultura, al hecho de haber sido un país subyugado, dependiente y estancado en su desarrollo. Nosotros vivíamos, según Arévalo, en la prehistoria del arte. 
¿Qué es lo "nuevo" en el Nuevo Teatro"? Yo diría que en primer lugar el cambio de repertorio: una rara mezcla de teatro clásico (Esquilo, Sófocles, Lope, Shakespeare), con teatro naturalista (Ibsen, Chejov, Williams, Miller), con teatro de vanguardia (Genet, lonesco, Becket, Brecht), en general un teatro desconocido o conocido solo como literatura. De golpe el teatro colombiano entra en contacto con un material enorme, vasto, universal, de distintas épocas y estilos, pero, sobre todo con el teatro moderno, ese teatro que se define por su contradicción con el Naturalismo. Es una época de búsqueda, la cultura teatral está abierta a muchas opciones y oposiciones, los grupos buscan su identidad, su razón de ser, en una sola década se cree poder absorber la experiencia de un siglo. Alguien lo ha llamado una etapa de gestación.

La otra cosa nueva son los nuevos grupos teatrales: el TEC de Cali, La Candelaria de Bogotá y el Teatro Popular de Bogotá (TPB). En la década del 60 son los núcleos de expansión de una cultura teatral inédita. Más adelante surgirán otros de indudable trascendencia, pero, ya estarán situados en otro momento, en otras coordenadas artísticas.

El tercer elemento son los festivales: el Festival internacional de teatro de Bogotá que va del 57 al 62; los festivales de arte de Cali entre el 61 y el 68; los festivales del teatro universitario que inician en 1966 y terminan en 1972. Los dos primeros tienen una suerte de carácter institucional, oficial, son espacios de divulgación "cultural", están ligados al proyecto de la burguesía liberal, a las aperturas ideológicas del Frente Nacional, la presencia del arte internacional con participación de las Embajadas es allí esencial. Con los festivales del teatro universitario hay un cambio radical, el teatro descubre su función social y política, desborda los marcos de la institucionalidad universitaria, se hace revolucionario.

Hay una cuestión más de fondo: el concepto de Nuevo Teatro (NT) ha estado sujeto a diferentes interpretaciones. Es un fenómeno cultural sobre el que se han tenido percepciones encontradas. A mi modo de ver hay dos elementos determinantes en su definición: la modalidad de ser un Teatro Experimental y la estrecha relación con la teoría brechtiana, que en los años cincuenta acometió la reforma del arte del teatro. Lo más importante que quiero señalar es la nueva visión práctica y teórica desde la cual se explora, se investiga y se lleva a escena un repertorio de obras de todas las épocas, universales, desde los clásicos griegos, pasando por el teatro del Siglo de Oro español, el Teatro Isabelino, el naturalismo europeo y norteamericano, hasta las vanguardias del Siglo XX. Se asume en una década intensa y acelerada todo el repertorio posible, pero, en clave experimental. De hecho, no había en el país un magisterio 
artístico consolidado que pudiera señalar cómo se montaban esas obras, eran solo textos, letras en un libro, era necesario descubrir los códigos de su escenificación, nada al parecer podía estar previamente definido o diseñado. Los actores en su mayoría eran jóvenes recién llegados, las escuelas estaban naciendo, ellos se van haciendo artísticamente en el proceso de creación de la puesta en escena. De esta manera la experimentación parece ser el camino natural del NT. Su gran riesgo es la especulación, la falta de rigor, la arbitrariedad, la ignorancia, no obstante, el Teatro Experimental se consagra a la búsqueda de nuevas formas de expresión, de nuevos métodos para el entrenamiento del actor, a cuestionar el viejo teatro de las compañías y su estética predeterminada, busca la interdisciplinariedad con las otras artes en el trabajo creativo. Frente al paradigma del teatro anterior con su sistema de producción y distribución comercial, el NT se desarrolla en un inédito campo de libertad artística e incertidumbre estética. Estos colectivos interclasistas, de jóvenes iracundos, se lanzan a un viaje a lo desconocido y abren a las nuevas generaciones la posibilidad de una vida dedicada al arte del teatro. Los mejores grupos, los más destacados, los más disciplinados, bajo la dirección de líderes clarividentes, crearán obras cuyo impacto ha quedado grabado en la memoria del teatro colombiano.

El segundo elemento que configura la estética del NT se llama Bertolt Brecht (18681956). Fue un poderoso reformador alemán del arte teatral a mediados del Siglo XX. Su ideario gira en torno al concepto del teatro épico, al que se identifica, también, como un teatro narrativo, opuesto a la estructura tradicional dramática. La teoría brechtiana está condensada en una especie de breviario laico titulado "El Pequeño Organón para el Teatro". Lo que de su pensamiento generó más interés en nuestro medio fue, su obstinada voluntad de hacer del teatro un estudio de la historia y las relaciones de poder en la sociedad de clases. En su teatro la dimensión política se constituye en una reflexión central. Brecht habla del compromiso, de la necesidad de tener un punto de vista, de sostener con firmeza una idea. Una buena parte de su dramaturgia está concebida desde una visión marxista de la historia y la sociedad. Desde una perspectiva artística el Teatro Épico es un teatro anti-naturalista, es decir, reivindica el estatuto de la teatralidad como el marco dominante de la representación. Condena el ilusionismo que pretende hacerle creer y sentir al espectador que aquello es una imagen viva de la realidad o la realidad misma. Creo importante citar un último rasgo de la teoría y la obra dramática de Brecht que influirá fuertemente en los directores y dramaturgos del NT, se trata de la relación crítica con los textos de la tradición teatral. Brecht es un adaptador y un 
reformador de la obra de Sófocles o Shakespeare o Shiller, toma esos textos sagrados e intocables para actualizarlos y los invierte o los tergiversa en función de nuevas interpretaciones. El defensor y divulgador más notable de Brecht en Colombia es el maestro Enrique Buenaventura. No es el único, pero, sí el más sistemático, su reflexión teórica es constante, como se puede ver en el libro "Máscaras y ficciones" de la Universidad del Valle. Es una summa antológica - de obras y artículos- realizada por el profesor Carlos Vásquez Zawadski: allí publica cinco artículos de Buenaventura sobre las teorías de Brecht que van de 1958 a 1978. En estos artículos son claras las ideas que retoma para sí del pensamiento brechtiano: rechaza lo que llama el confesionario sentimental del teatro de Stanislavski, las emociones autoprovocadas del actor que se identifica con el personaje, en teatro individualista o burgués, en cambio, adopta la separación radical del actor y su personaje, la narración de los hechos de la fábula en la lógica de las circunstancias sociales, las implicaciones políticas de una acción y no sus motivaciones psicológicas. De otra parte, se produce una toma de conciencia sobre la necesidad que el teatro se inscriba en los procesos de la lucha contra el fascismo, un teatro revolucionario, antiimperialista y anti-colonialista. Desde el punto de vista de las "formas" teatrales para la "puesta en escena", Buenaventura retomara de Brecht su interés por los espectáculos del teatro popular, particularmente el circo y el cabaret.

La influencia más duradera de Brecht se materializa primero en la obra dramática de Buenaventura, en la escritura de sus textos dramatúrgicos. Llama la atención que en el TEC nunca se llevaron a escena las obras del alemán. En cambio, Santiago García en Bogotá lleva a escena "Un hombre es un hombre" (1962), "Galileo Galilei" (1965) y "El alma buena de Se Chuan" (1969). También en Medellín se monta a Brecht, según lo refiere Gilberto Martínez en un artículo del citado libro de Colcultura, se trata de "Los fusiles de la madre Carrar" (1967). Seguramente en muchas otras partes se lo llevó a escena, en los festivales estudiantiles estaba presente, las ideas del teatro épico se van extendiendo de manera extraordinaria. El desafío que se plantea el NT bajo el liderazgo de Buenaventura en los 60 es el de crear una dramaturgia nacional y esta habrá de surgir en la clave del Teatro Épico.

El estudio más riguroso y sistemático que se ha hecho sobre el teatro del maestro Buenaventura es el realizado por la investigadora y especialista en el teatro latinoamericano Beatriz Rizk. Vamos a subrayar lo que ella dice en su libro Creación Colectiva: el legado de Enrique Buenaventura. La primera obra notable en el conjunto de su trabajo "A la diestra de 
dios padre" (1958), una adaptación-versión del cuento de Don Tomás Carrasquilla, ya en su segunda y tercera versión es sometida a un ajuste épico: los actores rompen el efecto de la cuarta pared y le hablan directamente al público, la figura de Cristo adopta el giro de un reformador social y el protagonista de la obra, Peralta, es delineado en el concepto brechtiano del "héroe problemático". Otra obra esencial en este período es "La tragedia del rey Christophe" (1961) donde al decir de Rizk utiliza varios recursos épicos para activar un distanciamiento crítico por parte del público. La obra tiene un prólogo y un epílogo a cargo de un personaje narrador, habla en tercera persona y hace comentarios, así como también inserta canciones y escenas de teatro dentro del teatro (122). Algo semejante sucede con la obra "Réquiem por el padre Las Casas" (1963) basada en la vida contradictoria del padre dominico, cuya defensa de los indios americanos provoca las famosas leyes de indias. Citemos dos obras más para cerrar estos ejemplos de la dramaturgia de Buenaventura: "Soldados" (1968) cuyo tema medular es la masacre de las bananeras del año 1928. Una obra con una "economía magistral de elementos" (Rizk 186), narrada por dos soldados, a los que se agregan un tamborilero y un boga que realizan múltiples funciones y se cambian de vestimenta frente al público asumiendo distintos roles en un juego de "complicidad" con el público. A la manera de las obras cortas de "Terror y miserias del Tercer Reich" de Brecht, el maestro Buenaventura escribe un mosaico de piezas cortas que titula "Los papeles del infierno" (1968) todas referidas a la época de la violencia en Colombia, una suerte de guerra civil no declarada entre liberales y conservadores.

Hasta aquí la dramaturgia de Buenaventura ha estado concebida en una matriz brechtiana, es decir, la organización de la fábula, la concepción funcional de los personajes, las significaciones que se quieren comunicar, corresponden al modelo del Teatro Épico. No hay duda que su obra es temáticamente original, los conflictos y el imaginario corresponden a la historia y a la sociedad latinoamericana. Igualmente es importante señalar que Buenaventura ha sido considerado un autor individual muy destacado, aunque integrado al TEC como colectivo orgánico, todavía en esta etapa hay una línea jerárquica invisible que va del autor, al director y a los actores, nadie todavía se ha cuestionado la independencia de esos roles. A finales de los 60 las cosas comienzan a cambiar. 


\section{Paradigma de la creación colectiva}

La primera cuestión que quiero plantear es si la Creación Colectiva (CC) es una ruptura o una continuidad con respecto al NT: si el NT y la CC son una y la misma cosa. Es un asunto polémico. Históricamente hay muchos elementos de continuidad, el solo hecho que el TEC y La Candelaria sean los principales protagonistas de la difusión de la CC y vengan de la etapa anterior, los sitúa en un orden cronológico ininterrumpido, pero, en la práctica, creo yo, la CC es un nuevo modo de producción y creación teatral. Si lo vemos en una perspectiva más amplia se puede hacer notar que de la gran explosión de grupos que emergieron de la década del 60 y no entran en los 70 a la CC, no por ello dejaron de ser parte de la experiencia transformadora del NT. Los dos más notables son el Teatro Popular de Bogotá (TPB) dirigido por Jorge Alí Triana y el Teatro Libre de Ricardo Camacho, ambos con una extraordinaria producción de montajes del repertorio universal, incluido Brecht, así como también, promovieron la creación de una dramaturgia nacional con autores como Jairo Aníbal Niño y Esteban Navajas, ampliamente premiados y reconocidos. Sin dar por el momento otras razones mi hipótesis es que la CC es una ruptura en la que se mantienen muchos presupuestos del Teatro Épico y el Teatro Experimental, pero, aparecen otros ingredientes estéticos antes desconocidos, es un nuevo modo de producción o creación teatral, además pondrá en marcha un movimiento de grupos, inédito en Colombia, coordinado por la Corporación Colombiana de Teatro bajo el liderazgo del TEC y La Candelaria. La naturaleza de la CC es poliédrica y multifacética, no solo ha habido muchos desacuerdos y malentendidos en torno a su definición, sino que con el paso de las décadas y las crisis que sobrevinieron, se hizo más compleja y difusa. Con la CC se partieron las aguas: se era partidario del autor individual o de la autoría del grupo. El ambiente de polarización política de la izquierda hizo que los primeros fueran partidarios del teatro burgués y los segundos de un teatro proletario o, dicho de otro modo, un teatro de entretenimiento cultural o un teatro políticamente comprometido. La década del 70 que es la "edad de oro" de la CC, será una década agitada por grandes conflictos internacionales y nacionales, movilizaciones populares, huelgas, dictaduras en el Cono Sur, procesos de descolonización en África y todo inscrito en el campo erizado de la guerra fría. Es un teatro que está presionado por los temas de actualidad en un contexto de gran confrontación ideológica. El teatro se convierte en un actor importante en los procesos de movilización social y política, en universidades, sindicatos, luchas agrarias y comunidades en conflicto con el orden establecido. 
Volvamos a los orígenes del teatro de CC a finales de los años 60, sobre lo cual hay diversas interpretaciones que voy a resumir en las tres más representativas: 1. Para María Escudero, directora teatral de la provincia del Rosario en Argentina, la CC nace en el TEC de Cali de la mano del Maestro Buenaventura (45). Esta afirmación, como las que vienen a continuación, surgieron en el Foro Internacional de Teatro (1975), celebrado en Cuba y registrado en el libro de Francisco Garzón Céspedes. 2. Para Manuel Galich, director de la revista "Conjunto", la CC es una corriente propia de América Latina, la cual surge de necesidades políticas y culturales internas de Latinoamérica, un fenómeno extraordinario que surge en países donde el teatro era casi inexistente, un hecho de fuerte contenido social que coincide con la emergencia de un proceso revolucionario, bajo la poderosa conmoción que provoca la Revolución Cubana en el continente y en el mundo (57). 3. Para Alonso Alegría, prominente dramaturgo peruano, es algo que surge a nivel mundial, sobre todo en Nueva York y San Francisco, al calor de las grandes agitaciones estudiantiles contra el racismo y la guerra del Vietnam. Grupos contestatarios, anti-sistema, como lo son el Living Theater, el Open Theater, el San Francisco Mime Troupe, el Bread and Puppet Theater, el Performance Groupe y el Teatro Campesino de Luis Valdez en el sur de California, con el que entrará en contacto el TEC en el año 69 (49). De igual importancia van a ser las rupturas propiciadas por los happening o performance de John Cage, pasando por el Teatro Laboratorio de Grotowski, el teatro experimental de Peter Brook, hasta el Odin Teatret de Eugenio Barba. Una larga y ancha cantidad extraordinaria de ideas y experiencias desconocidas, una vanguardia que irrumpe en los 70 con fuerza e impacta sobre el joven movimiento teatral colombiano en estado naciente. En la perspectiva de hoy se podría sacar esta conclusión: salvo María Escudero, nadie más ha insistido en su tesis, esa fue su particular experiencia, pero no la del continente y, de otra parte, lo que parece más lógico pensar es que hubo una combinación de factores históricos internos, como los plantea Galich, desde la Revolución Cubana y las corrientes internacionales citadas anteriormente y que Marco De Marinis denominó neo-vanguardia.

Entre los factores internos que creo le dan un giro al proceso del NT es la insurgencia del movimiento del Teatro Universitario (TU). A mi modo de ver fue un punto de inflexión determinante, como en la política nacional lo fue el fraude electoral del año 70, el que inaugura una época de convulsión y agitación inesperada y violenta. Entre el año 68 y 73 la corriente del Teatro Universitario se radicaliza ideológicamente, en buena parte bajo el impacto del Mayo 
Francés y sobre todo la Revolución Cultural China. En el libro de Mayra Natalia Parra titulado sintomáticamente "¡A teatro camaradas! Dramaturgia militante y política de masas en Colombia" de la Universidad de Antioquia, hay una importante cantidad de datos y referencias de este intenso proceso del TU entre los años 1965-75. El libro contiene lo esencial de esta época fundacional: el teatro se convierte en una parte integral de la máquina organizativa de los partidos revolucionarios, es un arma de acción y de lucha contra la dominación de la clase burguesa y el imperialismo norteamericano. De la corriente militante del teatro universitario nacieron muchas organizaciones artísticas y grupos teatrales de filiación partidaria como el FREGAL de Fausto Cabrera y el BTTAR (luego Pequeño Teatro) de Jairo Aníbal Niño, articulados al MOIR en Medellín y Cali, ambos grupos de agitación y propaganda de sus ideales políticos. En una clave menos emocional, más brechtiana, con una trayectoria artística profesional, pero, igualmente articulados a un compromiso ideológico con el Partido Comunista, estarán el TEC y LA CANDELARIA, quienes conciben su práctica teatral separada y autónoma de la inmediatez de las coyunturas de la acción política partidista, hay en ellos una dimensión estética inalienable de su condición de artistas, lo que hará posible su teorización de la CC.

Como teatro, el TU adopta un ideario "estético": se oponen al teatro profesional. Adoptan las tesis de Martín Weibel: hacemos un teatro de estudiantes, no de actores, no somos especialistas, no hacemos producciones escénicas, no tomamos riesgos financieros, adaptamos las obras a las circunstancias, las utilizamos como crítica social, vemos el teatro como un lugar para el desarrollo de la lucha ideológica (ctd en Parra 76). Es un teatro que no pretende ni formar actores, ni hacer montajes "artísticos", se conciben a sí mismos como colectivos de discusión y acción política, inscritos en las luchas populares. Es un teatro de aficionados, altamente politizados, imbuidos de una misión revolucionaria. Lo que les interesa es el proceso político no los resultados artísticos. A partir de 1966 se comienzan a realizar los Festivales Nacionales de Teatro Universitario que conducirán a la creación del sonado Festival de Teatro de Manizales, allí van a converger los Grupos Independientes que ya tienen una trayectoria profesional, un reconocimiento nacional, con los grupos diletantes de universitarios radicalizados, revolucionarios, intransigentes, que convierten los encuentros del festival en verdaderos campos de batalla ideológicos. La confrontación será inevitable, áspera, irreverente, los Grupos Independientes de actores profesionales serán acusados de hacer un teatro de "cámara", cerrado socialmente, dirigido a una "clase minoritaria", a una "élite intelectual" 
pequeño burguesa. Se sabe, está en el libro de Mayra Natalia Parra, que en el trasfondo hay una disputa entre la Nueva Izquierda surgida en los años 60, de filiación China y el viejo Partido Comunista, de filiación soviética (76). Una extraña consecuencia de la Guerra Fría. Con el cierre del Festival Universitario de Manizales en 1973 se inicia el declive del movimiento estudiantil y se abre paso la construcción de un movimiento de teatro independiente liderado por la Corporación Colombiana de Teatro (CCT).

Haciendo una síntesis, sigo la línea de esta hipótesis inicial: la CC surge a fines de los años 60 en el contexto de radicalización política del Teatro Universitario, bajo el impacto ideológico de la Revolución Cubana, Mayo del 68, la Revolución Cultural China y, determinada estéticamente por la oleada neo-vanguardista europea y norteamericana cuyo ideario de ruptura lo encabezan Artaud, Grotowski, Living Theatre, entre otros, así como el Teatro Documento de Peter Weis. Una enorme variedad de caminos diferenciados, una verdadera avalancha de cuestionamientos radicales que modificarán los conceptos del teatro, caminos que en general convergen en la oposición al teatro "profesional" u "oficial" de la cultura establecida.

Una primera cuestión de cómo opera el trabajo de los grupos de CC es su rechazo a la división del trabajo, es decir, a la idea consagrada de una jerarquía natural donde el autor y el director son las máximas autoridades. Lo que se plantea es que un grupo es un colectivo de actores y de artistas en igualdad de condiciones. Se promueve lo que se puede denominar como una estética de la participación: los actores en asamblea junto con el resto del equipo creativo toman las decisiones esenciales por consenso y determinan todo el funcionamiento del grupo. La igualdad entre los miembros de un grupo es el principio rector. Este colectivismo que se inspira en una estructura sindical va a generar muchas tensiones y confrontaciones dado el carácter propio y especializado de los procesos artísticos. Es claro que el modelo colectivo era una crítica que el teatro le hacía al capitalismo que fundaba la producción en la división del trabajo, esa alienación entre el trabajo intelectual de los que mandan y el trabajo físico que ejecuta. El proceso de creación de nuevas obras se hizo más largo, más intensas las discusiones, más diversos los puntos de vista y las subjetividades, las líneas de investigación se bifurcaban y amenazaban con empantanar llegar a un cierre definitivo. Como un antídoto contra la anarquía, el TEC elaboró un método para el trabajo colectivo, una rigurosa herramienta que ordenaba la participación creadora del grupo. Es importante señalar que este método operaba al interior de un grupo que tenía una trayectoria profesional ampliamente reconocida, en él 
reunían y decantaban las teorías semiológicas del análisis tanto literario como teatral más contemporáneo. No era un método fácil de asimilar, tuvo una divulgación extraordinaria, pero la mayoría de los grupos del movimiento teatral eran en su mayoría jóvenes diletantes. En este caso muy específico el método operaba como un férreo catalizador y organizador de las diferencias. No era este el caso de la mayoría de los grupos que se orientaban bajo el liderazgo del TEC y La Candelaria.

Otro punto focal de grandes discusiones fue el relativo al texto dramático. El lugar el texto dramático en el conjunto del hecho teatral se pone en cuestión. Hay una crisis de lo que se llama negativamente "teatro de palabras", frente al reivindicado "teatro gestual" o de "imágenes". La tradición había hecho dominante el lenguaje "verbal" en el teatro, lo esencial hasta ahora había sido el diálogo, desde Artaud por el contrario se buscaba la expresividad del cuerpo, del gesto, del movimiento, además los estudios semiológicos habían sistematizado los códigos de los lenguajes "no-verbales". El teatro de CC se orientó hacia la construcción del espectáculo, hacia los códigos escénicos. Se hace muy fuerte la distinción entre "texto literario" y "texto espectacular": dos objetos distintos cuya relación ha sido determinante en la historia del teatro. La CC puso el acento en el teatro como espectáculo y relativizó la importancia del texto como literatura. La frase lapidaria que se institucionalizó fue esta: "El teatro no es literatura". Fue un ataque consistente y sistemático contra el "texto-centrismo", este nuevo teatro tenía otras claves y estas estaban en las dinámicas de la escena. No deja de ser paradójico que pese a este rechazo del texto literario o a su centralidad, el método del TEC toma como referente de su estructura organizativa una obra escrita por el Maestro Buenaventura, "La Maestra". Igualmente, como síntoma de una ambigüedad no resuelta, es interesante contrastar esta concepción de la CC sobre el texto, con el valor y la centralidad del texto en el teatro de Brecht de cuyas teorías se seguirá alimentando el NT. No obstante, y este es un punto a tener en cuenta en lo que viene después, el teatro de CC no rompe del todo con una teatralidad literaria-narrativa, con una trama, unos personajes, una historia, un diálogo, es decir, no se arroja a la experiencia más radical del teatro "pos-dramático" que como lo ha definido Hans-Thies Lehmann se presenta como "encuentro de las artes" y este si, se desvincula de la hegemonía literaria.

Lo que si se produce en la CC es una inversión de la perspectiva: el factor primero, determinante será el espectáculo. Desde Aristóteles se había establecido que entre los componentes de la tragedia era el elemento menos importante. No seguirá siendo así en el 
teatro de vanguardia. Este escenocentrismo tiene sus inicios en el teatro naturalista en el que el director es el verdadero protagonista de todo el proceso creativo. La CC da un paso hacia adelante y traslada la iniciativa creadora de la puesta en escena a los actores. La lógica del teatro va a girar en torno a la escena o desde la escena, a los lenguajes "no-verbales", al cuerpo del actor y a los códigos de la representación. La escena es el punto de partida y de llegada, al texto escrito se lo considera en su articulación con el espectáculo y solo adquiere su verdadero significado en el acto de la representación. La relación entre literatura y espectáculo no debiera de ser excluyente, esa había sido la tradición, pero, desde Artaud el debate atraviesa todo el Siglo XX y no ha encontrado una solución. La crítica que pretendió valorar los textos dramáticos de la CC en su "autonomía" literaria y cuestionó su "calidad", su falta de rigor estético, el carácter aleatorio de su estructura episódica y la falta de personajes, se estrelló contra un muro de rechazo. La respuesta fue siempre esta: las obras de CC se deben estudiar en su proceso de creación, en el contexto de la representación, en su relación con el público, aisladas, como textos autónomos, como un puro objeto artístico, pierden su valor y su sentido. Además, habría que tener en cuenta que estas obras se presentaban como espectáculos abiertos, sometidas al foro o a la asamblea de un público implicado, activo, están allí como generadoras de una discusión política y ese es su sentido principal.

Hay un último elemento que probablemente sea el verdadero motor de esta modalidad teatral. La CC se plantea el problema de hacer un teatro popular y eso significaba dos cosas: un teatro "militante", articulado al proyecto de la revolución y, en segundo término, un teatro dirigido a un público de obreros, estudiantes y campesinos. El teatro hasta ahora había estado al servicio de una cierta clase media educada, a eso que con desprecio los marxistas llamaban la "pequeña burguesía", este nuevo teatro debía ser un instrumento al servicio de los movimientos sociales en ascenso, de las luchas obreras, sindicales, y de las movilizaciones agrarias. Para las organizaciones teatrales, vinculadas en su mayoría a los partidos de izquierda, el sistema democrático-burgués estaba en retroceso, se había agotado y la única solución a su crisis era una revolución violenta que condujera a una sociedad socialista. En un artículo titulado El arte no es un lujo, el Maestro Buenaventura dijo: "Aquí la revolución es el aire que se respira" (ctd en Parra 30) y eso era cierto. Esta era, igualmente, la visión y el propósito del Teatro Universitario, solo que estos eran abiertamente panfletarios, sectarios, dogmáticos y los Grupos Profesionales como el TEC y La Candelaria, defendían una cierta autonomía estética en sus 
obras. No hay duda que la teatralidad colectiva orientada hacia las masas populares genera nuevas formas de hacer el teatro, otro tipo de espectáculos para escenarios no convencionales, otras maneras de actuación, otras dramaturgias, como el caso ejemplar del Teatro Campesino de Luis Valdez en California, que colgaban de los actores pancartas con nombres de los personajes arquetípicos: "El patrón”, "El embaucador", "El huelguista" y "El esquirol”, obras didácticas para los campesinos chicanos en huelga. O el caso del San Francisco Mime Troupe cuya forma de representación fue denominada "teatro de guerrillas", grupo que retomó el estilo de las farsas medievales, las fiestas del carnaval, las comedias dell'arte italianas y las adaptaban a los temas de actualidad, las representaban en las plazas públicas, en las calles o en las asambleas de los obreros en paro, un teatro "pobre" en recursos escénicos, pero, determinado en su provocación política inmediata. Un punto clave del teatro de CC colombiano fue su marcado propósito de construir un teatro de identidad nacional, que recuperara nuestra historia y nuestro pasado. De allí obras tan emblemáticas como "La denuncia" del TEC, sobre el juicio en el Senado para destapar a los responsables de la masacre de las bananeras en 1928, y "Guadalupe años sin cuenta" sobre el líder guerrillero de los Llanos orientales asesinado en Bogotá después de haber negociado la paz con el gobierno. Una identidad con la cual se buscaba redescubrir la historia tantas veces tergiversada y ocultada.

Se puede concluir con esta reflexión final: el teatro de CC estuvo vigente entre los años 70-80, es decir, su época más representativa y de mayores logros, no obstante, sigue siendo para algunos grupos un método de referencia hasta hoy. No sobra aclarar que no hay un solo método, único, de CC e incluso en los mismos grupos, que como el TEC y La Candelaria siguen bajo sus presupuestos, este ha cambiado y ha soportado distintas crisis. Este teatro jugó un papel esencial en la construcción de otra visión sobre la función del teatro, así como hizo serios cuestionamientos sobre la historia y la sociedad colombianos. A partir de los años 90 comienza una nueva etapa para el teatro colombiano, marcada por tres hechos esenciales: la crisis de la CC, el surgimiento del Festival Iberoamericano de Teatro (1988) y la aparición de una nueva dramaturgia de autores. En este contexto se irá cuajando una nueva dramaturgia a la que genéricamente podremos denominar "pos-dramática". En un capítulo aparte vamos a desarrollar sus características, los grupos y los autores más representativos. 


\section{Referencias}

Buenaventura, Enrique. Máscaras y ficciones. Cali: Universidad del Valle, 1992. Impreso.

De Marinis, Marco. El nuevo teatro, 1947-1970. Barcelona: Paidós, 1988. Impreso.

García, Gabriel. Cien años de soledad. Buenos Aires: Suramericana, 1970. Impreso.

Garzón, Francisco (comp.). El teatro latinoamericano de Creación Colectiva. La Habana: Casa de las Américas, 1978. Impreso.

González, Fernando. El proceso del teatro en Colombia (Tomo II). Bogotá: Planeta, 1988. Impreso.

Hobsbawm, Eric. Historia del Siglo XX. Buenos Aires: Grijalbo-Mondadori, 1994. Impreso.

Oliva, Cesar y Torres, Francisco. Historia básica del arte escénico. Madrid: Cátedra, 1980. Impreso.

Lamus, Marina. Bibliografía Anotada del Teatro Colombiano. Bogotá: Círculo Alternativo, 2003. Impreso.

Parra, Mayra. jA teatro camaradas! Dramaturgia militante y política de masas en Colombia: Universidad de Antioquia, 2015. Impreso.

Pellettieri, Oswaldo. De Lope de Vega a Roberto Cossa. Buenos Aires: Galerna, 1994. Impreso.

Rizk, Beatriz. Creación colectiva, el legado de Enrique Buenaventura. Buenos Aires: Atuel, 2008. Impreso.

Rizk, Beatriz. Buenaventura: la dramaturgia de la creación colectiva. México: Grupo Editorial Gaceta, 1991. Impreso.

Szondi, Peter. Teoría del drama moderno. Madrid: Clásicos Dykinson, 2011. Impreso. 